\title{
Het gebruik van magnetoencefalografie als hersenbeeldvormingstechniek voor het bestuderen van neurale processen bij ontwikkelingsstotteren
}

\author{
Luc De Nil ${ }^{1,2}$, Douglas Cheyne ${ }^{1,3}$, Anna Mersov $^{1}$ \\ ${ }^{1}$ Department of Speech-Language Pathology, University of Toronto, Canada \\ ${ }^{2}$ Logopedische en Audiologische Wetenschappen, Katholieke Universiteit Leuven, Belgie \\ ${ }^{3}$ Hospital for Sick Children Research Institute, Toronto, Canada
}

\begin{abstract}
Samenvatting
Hersenbeeldvormingsonderzoek heeft belangrijke functionele en structurele verschillen tussen de hersenen van mensen die stotteren en typisch vloeiende sprekers onthuld. Deze verschillen hebben onderzoekers toegestaan om het ontstaan en de ontwikkeling van stotteren bij kinderen en volwassenen beter te begrijpen. Echter, tot voor kort was het voor hersenonderzoekers moeilijk, zo niet onmogelijk, om neurale processen tijdens de planning en productie van individuele gestotterde of vloeiend gesproken woorden te onderzoeken. Een relatieve nieuwe hersenbeeldvormingstechniek, magnetoencefalografie (MEG), biedt onderzoekers nu de mogelijkheid om subtiele modulaties in neurale processen op het milliseconde niveau te analyseren terwijl een spreker zich voorbereidt op het zeggen van een individueel woord. In dit artikel introduceren we MEG en de wijze waarop het gebruikt kan worden om spraak te bestuderen, gevolgd door een discussie van enkele recente bevindingen omtrent stotteren. Vervolgens illustreren we het gebruik van MEG voor de studie van vloeiende en gestotterde spraakproductie met behulp van voorlopige resultaten van twee recente studies uitgevoerd bij onze onderzoeksgroep. In de eerste studie onderzochten we het tijdsverloop van neurale activatie tijdens zowel een spreek- als een non-spreek (knopdruk) taak. De resultaten onthulden vergelijkbare resultaten voor de spreek- en non-spreekktaken, en lieten zien hoe taakcomplexiteit neurale verwerking kan beïnvloeden. Studie 2 rapporteert resultaten van een studie die stotterende en niet-stotterende sprekers vergeleek tijdens spraakproductie. De resultaten suggereerden dat verschillen in de betrokkenheid van de motorcortex kunnen worden getimed om samen te vallen met spraakplanning voorafgaand aan bewegingsinitiatie. Dergelijk onderzoek toont aan dat MEG veelbelovend is om ons begrip te bevorderen van neurale triggers die geassocieerd worden met het optreden van stotteren in spraak. De bevindingen kunnen klinisch onderzoekers in staat stellen om te
\end{abstract}

Correspondentieadres: Luc De Nil, Ph.D., Department of Speech-Language Pathology, Rehabilitation Sciences Building, Faculty of Medicine, University of Toronto, 160-500 University Avenue, Toronto, ON M5G 1V7, Canada

E-mail: luc.denil@utoronto.ca 
zoeken naar manieren om klinische interventie aan te passen teneinde de rol van dergelijke triggers te minimaliseren of te voorkomen.

\section{Summary}

Brain imaging research has revealed important functional and structural differences between the brains for people who stutter and typically fluent speakers. These differences have allowed researchers to better understand the onset and development of stuttering in children and adults. However, until recently it has been difficult if not impossible for brain researchers to investigate neural processes during the planning and production of single stuttered or fluent words. A relatively new brain imaging technique, magnetoencephalography (MEG), now provides researchers the opportunity to analyze subtle modulations in neural processes at the millisecond level as a speaker prepares to say a single word. In this article, we introduce MEG and describe how it can be used to study speech, followed by a discussion of some recent findings in stuttering. We then illustrate the use of MEG for the study of fluent and stuttered speech production using preliminary results of two recent studies completed by our research team. In the first study, we investigated the time course of neural activation during both a speech and a non-speech (button press) task. The results revealed similar results for the speech and non-speech tasks and showed how task complexity can influence neural processing. Study 2 reports results from a study comparing stuttering and nonstuttering speakers during speech preparation. The results suggested that differences in motor cortex engagement can be timed to coincide with speech planning prior to movement initiation. Such research shows that MEG has great promise to advance our understanding of neural triggers associated with the occurrence of stuttering in speech. Its findings may allow clinical investigators to search for ways to adapt clinical intervention in order to minimize or prevent the role of such triggers.

\section{Inleiding}

Stotteren is een spraakstoornis die wordt gekenmerkt door onvrijwillige verstoringen van de normale spraakstroom. In dit artikel bespreken we hoe magnetoencefalografie (MEG) gebruikt kan worden om neurale processen te onderzoeken die ten grondslag liggen aan stotteren. Eerst zullen we een aantal van de basisprincipes van MEG scanning beschrijven, en een kort overzicht geven van relevante literatuur. Daarna volgt een toelichting van de scantechniek gebaseerd op resultaten die tot op heden verkregen zijn in onze onderzoeksgroep. We zullen de term personen die stotteren (PWS) gebruiken bij de verwijzing naar stotterende sprekers in het algemeen. Waar nodig zullen we een onderscheid maken tussen kinderen die stotteren (CWS) en volwassenen die stotteren (AWS). Niet-stotterende sprekers worden gewoonlijk aangeduid als typisch vloeiende sprekers (TFS) om het feit dat, hoewel de spraak bij deze personen overwegend vloeiend is, het niet verstoken is van onvloeiendheden. 
Clinici en onderzoekers beschouwen klank- en lettergreepherhalingen, verlengingen en blokkades van spraak als de kernkarakteristieken van ontwikkelingsstotteren. Deze types van onvloeiendheden kunnen geïdentificeerd worden in de meeste personen die stotteren, in verschillende frequenties, maar zijn zeer zelden waar te nemen in typisch vloeiende sprekers (Bloodstein \& Bernstein-Ratner, 2008). Normaal gesproken heeft stotteren zijn ontstaan in de kinderjaren, waarbij het aangeduid wordt als ontwikkelingsstotteren. Echter, men kan ook vormen van stotteren vinden die optreden op volwassen leeftijd, ofwel na een neurologische (verworven neurogeen stotteren) of psychologische (psychogeen stotteren) conditie (De Nil, Jokel \& Rochon, 2007). In dit artikel zullen we ons vooral richten op onderzoek naar ontwikkelingsstoornissen.

Ontwikkelingsstotteren wordt meestal als eerste waargenomen tussen de leeftijd van twee tot zes jaar (Yairi \& Ambrose, 2013). De aandoening wordt vaker waargenomen bij mannen dan bij vrouwen, met een geslachtsverhouding van 3-4:1 bij oudere kinderen en volwassenen (Drayna et al., 1999). Hoewel onderzoek heeft aangetoond dat ongeveer 60 tot 80 procent van de kinderen zal herstellen van stotteren binnen twee jaar na het begin, zal 20 tot $40 \%$ van de kinderen die beginnen te stotteren een chronische ontwikkelingsstoornis ontwikkelen (Bloodstein \& Bernstein-Ratner, 2008; Yairi \& Ambrose, 1999). Op dit moment is ons begrip van de oorzaken voor het ontstaan, verbetering of chroniciteit van deze spraakvloeiendheidsstoornis nog niet compleet.

Gedurende de afgelopen 90 jaar hebben onderzoekers mogelijke oorzaken van ontwikkelingsstotteren onderzocht. Een van de eerste wetenschappelijk gefundeerde theorieën werd voorsteld door Lee Travis, een psycholoog, en Samuel Orton, een neuroloog (Orton, 1928), die poneerden dat stotteren kon verklaard worden door een gebrek aan het ontwikkelen van een eenzijdige (voornamelijk links) cerebrale dominantie tijdens de vroege ontwikkeling. Hoewel hun hypothese dat dit gebrek aan cerebrale dominantie het gevolg was van gedwongen rechtshandigheid van aangeboren linkshandige kinderen al lang losgelaten is, heeft hun aandacht voor het bestuderen van neurale processen als een manier om de etiologie en ontwikkeling van stotteren te begrijpen bewezen zeer vooruitziend te zijn.

Sinds dit eerste werk door Orton en Travis zijn er veel verschillende verklarende theorieën over stotteren voorgesteld. De focus van dergelijke theorieën heeft onder andere psychologische factoren (Sheehan, 1953), omgevingsinvloeden (Johnson, 1959), taalfactoren (Bloodstein \& Bernstein-Ratner), genetica (Ambrose, Cox \& Yairi, 1997) en motorische ontwikkeling (De Nil, 1999) verkend. Momenteel lijken de meeste clinici en onderzoekers het er over eens te zijn dat een multifactoriële beschouwing over het ontstaan en de ontwikkeling van stotteren het best de inzichten uit vele jaren van wetenschappelijk onderzoek en klinische observaties weerspiegelt.

Aanzienlijke vooruitgang in ons begrip van ontwikkelings- en verworven stotteren is voortgekomen uit recent onderzoek met hersenbeeldvormingstechnieken zoals Positron Emission Tomography (PET) en functional Magnetic Resonance Imaging (fMRI). Hiermee kun- 
nen onderzoekers verschillen in functionele activeringen en structurele integriteit van neurale systemen van stotterende en typisch vloeiende sprekers en tussen gestotterde en vloeiende spraak bestuderen. Een van de centrale bevindingen die voortkomen uit deze studies is de cruciale rol van atypische spraakgerelateerde hersenverwerking bij mensen die stotteren, tijdens spraak maar ook in rust. Voor lezers die geïnteresseerd zijn in een meer gedetailleerd overzicht van hersenbeeldvormingliteratuur over stotteren zijn er een aantal recente artikelen en boekhoofdstukken beschikbaar die dit snelgroeiende gebied van onderzoek samenvatten (De Nil, 2004; De Nil \& Beal, 2015). In dit artikel willen we focussen op het gebruik van magnetoencefalografie (MEG), een relatief recente benadering in het bestuderen van ontwikkelingsstotteren.

\section{Een introductie in magnetoencefalografie}

Magnetoencefalografie (MEG) is een steeds populairder neurobeeldvormingstechniek die laag-amplitude ( $\approx 10$ tot 1000 femtoTesla) magnetische velden meet die geproduceerd worden door onderliggende neurale activiteit in de hersencortex (Hämäläinen et al., 1993). Wanneer neuronen actief zijn, generen de elektrische signalen die door de neuronen reizen een magnetisch veld. De sterkte van dit magnetisch veld hangt onder andere af van (1) het niveau van activiteit in de neuronen en (2) het aantal neuronen dat actief is. Signaalmiddeling wordt gebruikt voor het identificeren en isoleren van het activiteitsafhankelijke magnetische signaal uit de bredere totale hersenactiviteit.

Moderne MEG systemen leveren zeer preciese metingen van de verdeling van veranderingen in het magnetisch veld over de hoofdhuid met behulp van helmvormige toestellen die rijen van 100 of meer supergeleidende sensoren bevatten. Figuur 1 toont een deelnemer zittend in de MEG in het Hospital for Sick Children in Toronto. Gecombineerd met geavanceerde bronreconstructie-algoritmen kan de verdeling van het magnetisch veld gebruikt worden voor het milliseconde per milliseconde genereren van complete hersenbeelden van voortdurende hersenactiviteit bij uiteenlopende cognitieve en sensorimotorische taken (Cheyne \& Papanicolaou, 2015).

Vergeleken met conventionele beeldvormingsmethoden zoals fMRI, PET en elektroencefalografie (EEG), geeft MEG de unieke combinatie van hoge tijdsresolutie $(<1 \mathrm{~ms})$ en goede ruimtelijke resolutie (3-5mm) metingen van neurale activiteit. MEG kan ook gecombineerd worden met MRI-scans om neurale activiteit in kaart te brengen op een anatomisch beeld van het brein van een deelnemer. Zodoende heeft MEG de mogelijkheid om snelle veranderingen in hersenactiviteit van verschillende hersengebieden tegelijkertijd vast te leggen, evenals veranderingen in lopende ritmische hersenactiviteit. Dit laatste is bijzonder bruikbaar voor de studie van geïnduceerde corticale oscillaties, i.e., tijdelijke modulatie van ritmische activiteit geïnduceerd door het optreden van een actie of stimulusgebeurtenis, maar niet noodzakelijkerwijs fase-vergrendeld met een bepaald tijdsmoment (en daarom niet versterkt door signaalmiddeling). 


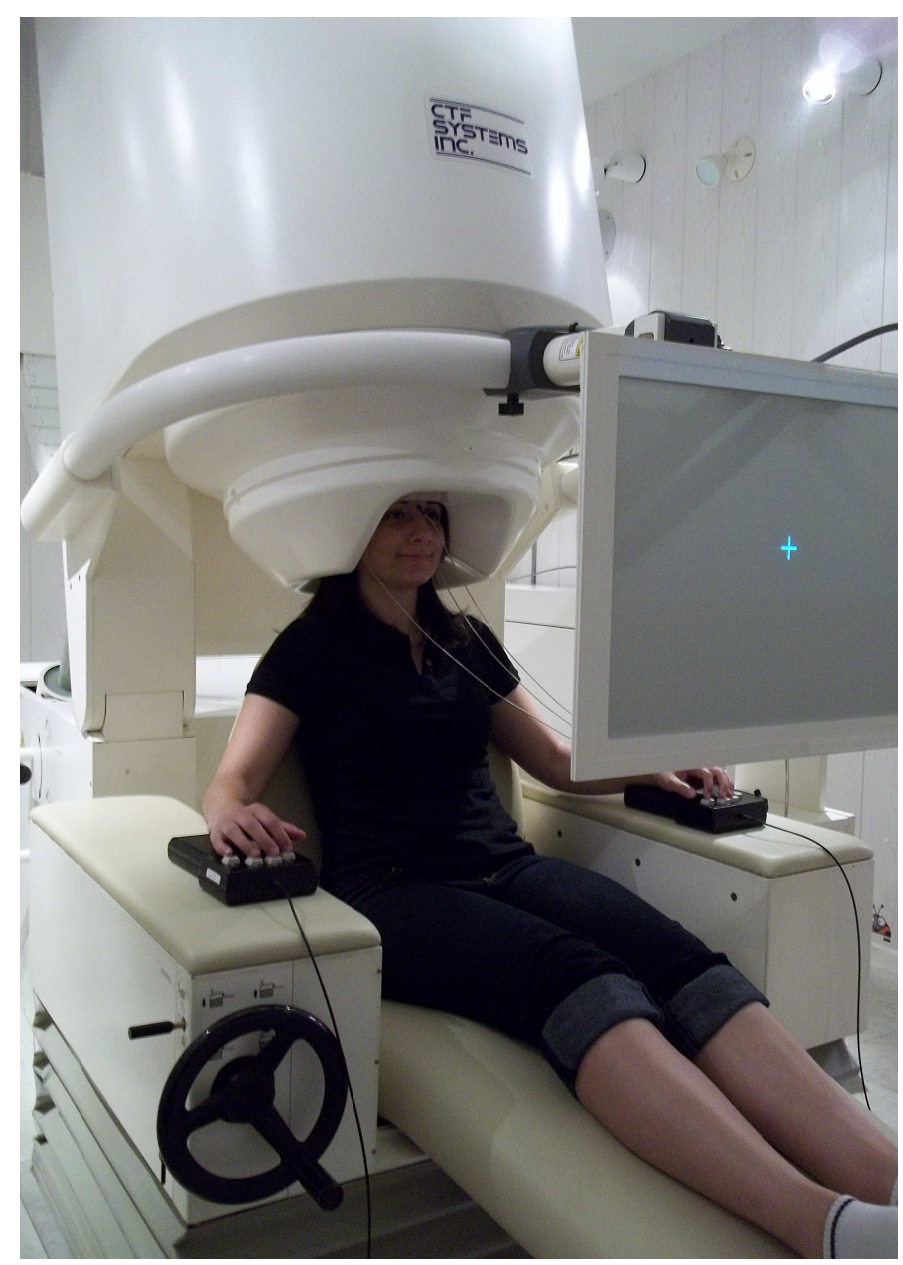

Figuur 1: Deelnemer gezeten in de magnetoencefalografie scanner in de Hospital for Sick Children beeldvormingsfaciliteit tijdens een knopdruk en spraak experiment. De aansluitingen voor de EMG elektroden om spraakbewegingen op te nemen zijn zichtbaar.

Hoewel hoofdbewegingen MEG opnamen kunnen verstoren en deelnemers daarom vereist worden stil te zitten - niet anders dan andere hersenbeeldvormingstechnieken zoals fMRI, is MEG met succes gebruikt om hersenactiviteit te bestuderen bij motorische taken, met inbegrip van overte spraak. In tegenstelling tot EEG worden MEG opnamen niet verstoord door elektrische stromen die afkomstig zijn van spieractiviteit die door de hoofdhuid naar de elektroden verspreiden tijdens openlijke spraak, en bronbeeldvormende methoden van MEG kunnen kleine hoofbewegingen tolereren die problematisch kunnen zijn voor fMRI opnamen. MEG heeft last van enkele beperkingen in termen van lagere gevoeligheid voor activiteiten in radiaal gericht corticale vouwen, of voortvloeiend uit zeer diepe structuren, evenals een mindere beschikbaarheid en mogelijk hogere kosten. Hierdoor blijven waarnemingen grotendeels beperkt tot het corticale oppervlak van de hersenen, waardoor 
het moeilijk of onmogelijk wordt activatiepatronen in hersengebieden te onderzoeken zoals de basale ganglia en cerebellum - gebieden die mogelijk een belangrijke rol in stotteren hebben (Alm, 2004; De Nil, et al., 2001). Ondanks deze beperkingen heeft MEG steeds meer een belangrijke en aanvullende rol in de studie van menselijke hersenfunctie, waaronder die betrokken bij stotteren, samen met andere hersenmetingen zoals EEG en functionele MRI.

MEG biedt een aantal voordelen voor de studie van ontwikkelingsstotteren omdat het vaak als minder intimiderend wordt ervaren door deelnemers, vooral kinderen, dan fMRI. MEG leent zichzelf voor een rustige scanomgeving die de observatie en registratie van overte spraakproductietaken verbetert. Het staat deelnemers ook toe getest te worden in een zittende houding, wat een meer natuurlijke houding is voor spraakproductie ten opzichte van de rugligging die noodzakelijk is in fMRI onderzoek (Figuur 1).

\section{MEG studies van alfa and bèta oscillaties tijdens het bewegen}

Het is al lang bekend dat bewegingen frequentiespecifieke veranderingen in de elektrische activiteit van de hersenen opwekken, met name in de bèta $(15-30 \mathrm{~Hz})$ en alfa (of mu) (8-14 $\mathrm{Hz}$ ) frequentiebanden. Deze stijgingen en dalingen in spectrale sterkte worden respectievelijk event-related synchronization (ERS) en desynchronization (ERD) genoemd, en worden opgewekt tijdens en na de voorbereiding en uitvoering van vrijwillige bewegingen (voor een overzicht zie Cheyne, 2013).

Een aantal studies hebben MEG gebruikt om neurale oscillatiepatronen geassocieerd met motorische bewegingen te bestuderen. Deze studies hebben aangetoond dat ERD en ERS gedurende hand- en ledemaatbewegingen ontstaan uit gebieden van de sensorimotorische cortex (Salmelin \& Hari, 1994; Hari et al., 1997; Taniguchi et al., 2000; Schnitzler et al., 2006; Jurkiewicz et al., 2006). Vergelijkbare hersenreacties kunnen worden waargenomen tijdens orofaciale bewegingen, inclusief tongbewegingen (Loose et al., 2001), kaakopening (Shibukawa et al., 2004) en slikken (Dziewas et al., 2003, Furlong et al., 2004). Studies bij niet-humane primaten hebben aangetoond dat sensorimotorische cortexritmes, met name bèta-bandoscillaties, verschillen weerspiegelen in lokale veldpotentialen in de sensorimotorische cortex, in het bijzonder de primaire motorcortex of Brodmann gebied 4 (Kilavik et al., 2011; Murthy \& Fetz, 1992; Sanes \& Donoghue, 1993). Deze gebieden zijn gerelateerd aan voorbereiding en sensomotorische integratie van bewegingen (Murthy \& Fetz, 1996) gekenmerkt door een langdurige onderdrukking van alfa- en bèta-sterktes die $500 \mathrm{~ms}$ beginnen voor de bewegingsstart. Deze onderdrukking ontstaat meestal bilateraal uit de regio's van de post-centrale gyrus. In tegenstelling tot alfa-oscillaties laat de bèta-bandsterkte een gemarkeerde verhoging in sterkte zien gedurende post-beweging, die de uitgangssterkte van de voor-beweging overschrijdt. Deze toename begint ongeveer 300 tot $400 \mathrm{~ms}$ na het beeindigen van EMG-activiteit en houdt meer dan 500ms aan. Deze post-movement beta rebound (PMBR) kan gelokaliseerd worden in bilaterale gebieden van de pre-centrale gyrus, meestal met grotere lateralisatie in de contralaterale hemisfeer. PMBR lijkt tijdvergrendeld te zijn 
met het einde, en niet met de start van de beweging. Men heeft voorgesteld dat deze PMBR de beëindiging van aanhoudende afferente of reafferente invoer naar de primaire motorcortex na individuele of herhaalde bewegingen weerspiegelt (Cassim et al., 2001). Sommigen hebben gesuggereerd dat deze waarnemingen wijzen op een anti-kinetische rol van bèta-oscillaties die de handhaving van de huidige motortoestand bevorderen (Engel \& Fries, 2010; Gilbertson et al., 2005). Overeenkomstig kan de pre-bewegingsonderdrukking van bèta-oscillaties binnen deze corticale-subcorticale loops een algemeen faciliterend effect op bewegingsinitiatie hebben (Jenkinson and Brown, 2011). Niet iedereen is volledig eens met deze visie, echter, gezien dat bèta-onderdrukking voorgaande aan de bewegingsstart ook gekoppeld is aan aspecten van hogere orde motorische planning, zoals de mate van zekerheid van de bewegingsparameters voor multiple choice responstaken (Tzagarakis et al., 2010). Onderzoek gericht op het begrijpen van de functionele rol van deze frequentiemodulaties duurt voort.

\section{MEG studies van spraakproductie}

MEG is recent ook gebruikt voor de studie van spraak-geassocieerde neurale processen. Vergelijkbaar met motorische bewegingen van ledematen, zijn er veranderingen in de alfa- en bèta-oscillaties waargenomen over sensorische en motorische gebieden tijdens spraakvoorbereidingstaken (Gehrig et al., 2012; Jenson et al., 2014; Liljeström et al., 2014; Salmelin et al., 2000). Bijvoorbeeld in een studie uitgevoerd door Gehrig et al. (2012) werden typisch vloeiende sprekers visueel gecued of een aanstaande zinsequentie overt of covert gelezen moest worden. De resultaten lieten zien dat de voorbereiding op overt lezen sterke oscillatieonderdrukking in spraakgerelateerde gebieden induceerde. Met name werd er een afname in alfasterkte waargenomen in de linker temporaalkwab, terwijl bètaonderdrukkking werd waargenomen in de bilaterale parietale kwab en het linkse articulatorische motorgebied. In een meer recente study, Jenson et al., (2014) vroeg volwassen deelnemers om syllabes hardop uit te spreken wanneer een cue werd gepresenteerd, en observeerde een geinduceerde onderdrukking van alfa- en bèta-activiteit in de linker premotor- en primaire motorcortex beginnend $300 \mathrm{~ms}$ na de cue om te spreken.

Een interpretatie van bèta-onderdrukking die wordt waargenomen in de motorcortex tijdens spraakvoorbereiding, is dat dit het proces van feed-forwarding van het spraakplan naar de motorische en sensorische gebieden betrokken bij de regulering en monitoring van spraakproductie weerspiegelt. Daarentegen is de waargenomen alfa-onderdrukking in de auditieve cortex geacht de priming van spraakgerelateerde auditieve feedback te reflecteren (Bowers et al., 2013; Gehrig et al., 2012; Liljeström et al., 2014). Echter, gezien de complexe neurale interactie inherent aan spraakvoorbereiding en productie, is het niet verrassend dat een significant niveau van neurale coherentie, vooral in de hogere gebieden van de bètaband (25-31 Hz), ook bilateraal is waargenomen, met name tussen de primaire motor- en premotorcortexen, evenals de inferiore en midden temporale gyri in de auditieve cortex (Alho et al,. 2014; Liljeström et al,. 2014). 


\section{MEG studies van ontwikkelingsstotteren}

Tot op heden hebben een aantal onderzoekers MEG data verkregen bij kinderen en volwassenen die stotteren gerapporteerd. De resultaten van deze studies hebben een aantal verschillen aan het licht gebracht in neurale oscillaties in de vloeiende spraakproductie van volwassenen en kinderen die stotteren. Bij volwassenen die stotteren hebben onderzoekers abnormaal hoge bèta-activiteit over de cortex gerapporteerd (Ozge, 2004), terwijl anderen een rechtsgelateraliseerde bèta-onderdrukking in de mond-motorcortex gedurende spraak hebben waargenomen (Salmelin, 2000). Etchell et al. (2014) hebben gesuggereerd dat de aanwezigheid van atypische bèta-oscillaties op het corticale niveau een manier kan zijn om te compenseren voor oscillatie-afwijkingen binnen sub-corticale basale ganglia-loops. Als dat zo is, kunnen dergelijke afwijkingen en hun compensaties leiden tot onnauwkeurige timingsvoorspellingen en temporele verwerking in stotterende sprekers. In een studie van auditieve verwerking bij kinderen die stotteren, hebben Beal et al. (2011) waargenomen dat hoewel de totale sterkte van oscillaties geen onderscheid maakte tussen kinderen die wel en niet stotteren, de timing van de piek-oscillaties verschilde tussen de twee groepen, mogelijk wijzend op timingsverschillen die spraakproductie kunnen beïnvloeden.

In een recent voltooid onderzoek in ons laboratium analyseerden we bèta-oscillaties gedurende de voorbereiding op overte spraakproductie in AWS. Onze resultaten lieten zien dat hoewel de spraak vloeiend was, AWS een sterkere bèta-synchronisatie lieten zien in de linker mondcortex, voorafgaand aan spraakinitiatie, dan in een controlegroup met typische vloeiende sprekers. Deze synchronisatie werd gevolgd door een verhoogde bèta-onderdrukking in de bilaterale mond-motorcortex. Het is interessant om op te merken dat in de meeste motorbewegingen deze bèta-synchronisatie is geacht een rol te spelen in het handhaven van de huidige motortoestand, en daarom de initiatie van nieuwe motorbewegingen na de bewegingsbeëindiging onderdrukt (Engel \& Fries, 2010; Pfurtscheller \& da Silva, 1999). Dit suggereert dat de geobserveerde verhoogde synchronisatie zou kunnen wijzen op een verhoogde toestand van onderdrukking van de motorcortex in AWS, en de daarop volgende inadequate voorspellende timing en regulering van de spraakmotorplanning. De vervolgens waargenomen bèta-onderdrukking zou dan gerelateerd kunnen worden aan inspanningen om vloeiende spraakinitiatie te faciliteren, en mogelijkerwijs wordt de rechter hersenhelft gerekruteerd voor aanvullende ondersteuning.

\section{MEG studies van individuele stottermomenten}

Gegeven de nauwkeurige tijdsresolutie van MEG, is deze beeldvormingstechniek bij uitstek geschikt voor het bestuderen van neurale activiteit verbonden met individuele gestotterde of vloeiend gesproken woorden. De eerste studies gericht op het vergelijken van vloeiende en gestotterde uitingen zijn pas recentelijk gerapporteerd, en de bevindingen zijn nog voorlopig. Niettemin, de resultaten die tot nu toe zijn gegenereerd bieden een grote belofte voor het verbeteren van ons begrip van stotteren. In een studie van Sowman en collega's (Sowman et al., 2012), lieten observaties bij een individueel proefpersoon zien dat gevallen van 
blokkeren tijdens klinkerproductie waren geassocieerd met afgenomen activiteit in de linker inferieure frontale cortex. De onderzoekers stelden voor dat deze vermindering een weerspiegeling zou kunnen zijn van een ontoereikend voorbereidend articulatieplan, wat geresulteerd zou kunnen hebben in de geobserveerde onvloeiendheden. Vanhoutte et al. (2016) vond dat de signaalamplitude geassocieerd met event-gerelateerde potentialen significant was gereduceerd voorafgaand aan gestotterde woorden. Deze vindingen, echter, werden gelimiteerd door het feit dat, hoewel de geobserveerde signaalmodulaties van gestotterde woorden significant verschilden van die van vloeiende woorden, er geen verschillen werden gevonden tussen stotterende en typisch vloeiende deelnemers, waardoor het moeilijk wordt om de data te koppelen aan de aanwezigheid van stotteren.

We analyseerden en vergeleken modulatie in neurale oscillaties tijdens spraakvoorbereiding in een group van AWS en typisch vloeiende sprekers (Mersov et al., 2016). De AWS lieten zowel sterkere bèta-onderdrukking als bèta-synchronisatie zien in de bilaterale mondmotorcortex. Verder, wanneer vergeleken met de controledeelnemers, rekruteerden de stotterende volwassenen de rechter mond-motorcortex significant eerder in de spraakvoorbereidingsfase. We interpreteerden deze vindingen als wijzend op een sterker geremd motorsysteem dat een sterkere bèta-onderdrukking nodig heeft om zich af te sluiten voorafgaand aan spraakinitiatie. Dit zou kritische verschillen in het spraak-motornetwerk van AWS en typisch vloeiende sprekers, die optreden voorafgaand aan spraak, aan het licht brengen. In een gerelateerde study vergeleken we de motorvoorbereiding voorafgaand aan 314 gestotterde woorden afkomstig van een group van acht AWS met hun vloeiende uitingen (Mersov et al., ingediend). In zowel de stotterende en de typisch vloeiende sprekers induceerde de motorvoorbereiding voorafgaand aan de spraakaanvang bèta-onderdrukking in de bilaterale mond-motorcortex. Hoewel de waargenomen verschillen tussen de vloeiende en gestotterde woorden niet significant werden, namen we een trend waar in de richting van een verlaagde en vertraagde bèta-onderdrukking voorafgaand aan stotteren in de linker mondmotorcortex. Ondanks dat bevestiging in follow-up studies is aanbevolen, geven deze bevindingen een belangrijke rol aan van de linker inferiore frontale gyrus en ventrale linker premotorcortex in de voorbereiding en timing van motorspraakplannen bij stotteren.

In het vervolg van dit artikel zullen we de toepasbaarheid van MEG bij spraak- en stotteronderzoek verder illustreren aan de hand van twee preliminaire studies die recent zijn uitgevoerd in het Speech Fluency Laboratory van de University of Toronto.

\section{Studie 1: een vergelijkend onderzoek van spraak en knopdruk motorbewegingen}

Eerder onderzoek heeft een overlap gesuggereerd in neurale processen betrokken bij de controle van spraak- en non-spraakbewegingen, niet alleen bij typisch vloeiende sprekers, maar ook bij sprekers die stotteren (Chang et al., 2009). Het doel van deze preliminaire stu- 
die (Kwon et al., 2015) was te onderzoeken of MEG gebruikt kon worden om modulaties in neurale oscillaties tijdens verbale en non-verbale motortaken te vergelijken met behulp van MEG. Een bijkomend doel van de studie was de invloed van taakcomplexiteit op neurale processen te onderzoeken. Zestien typisch vloeiende sprekers (8 mannen en 8 vrouwen; gemiddelde leeftijd 26 jaar) werd gevraagd twee taken te voltooien: een knopdruktaak gedurende welke de deelnemers gepresenteerd werden met en gevraagd om op knoppen te drukken die correspondeerden met een serie van 4 willekeurig geordende nummers. Elk nummer correspondeerde met een specifieke vingerdruk. De helft van de sequenties werd makkelijk geacht (4 identieke nummers) en de andere helft complex (4 verschillende nummers). In een parallelle taak werden deelnemers gevraagd om $4 \mathrm{CV}$ syllabes overt te produceren die ofwel eenvoudig (dezelfde syllabe) dan wel complex (verschillende syllabes) waren. Temporele modulaties in bèta-frequenties werden onderzocht met behulp van een beamformer bronlokaliseringsalgoritme en virtuele sensoranalyse aan de hand van software ontwikkeld in het Hospital for Sick Children (cheynelab . utoronto . ca/brainwave).

Figuur 2 toon de tijd-frequentiegrafiek verkregen voor beide taken. De tijd is uitgezet op de X-as, en de frequentie van neurale oscillaties is uitgezet langs de Y-as. De horizontale gestippelde lijnen geven de bèta-frequentie zone aan. Rood geeft een toename aan in eventgerelateerde synchronisatie, terwijl blauw een afname in synchronisatie aangeeft, met de kleurintensiteit als procentuele verandering in de respons. De verticale solide lijn geeft de timing van de reactiecue aan.

Figuur 3 toon dezelfde data, maar dit keer als percentage verandering in de tijd. De solide lijn toont het knopdrukantwoord, en de gestippelde lijn is de spraakreactie. Blauwe lijnen worden geassocieerd met de makkelijke reactie en rood is de complexe reactie. Nogmaals, de verticale solide lijn geeft de presentatie van de reactiecue aan.

De resultaten toonden een grotere afname in pre-beweging bèta-ERD bij makkelijke reacties dan bij complexe reacties, wat kan wijzen op de langere tijd of moeite die nodig is voor het neurale systeem in voorbereiding voor de meer complexe bewegingen. Na voltooiing van de beweging was de bèta-ERS sterker voor de complexe taken, wat op zijn beurt suggereert dat zulke taken geassocieerd zijn met sterkere proprioceptieve feedbackverwerking en grotere cognitieve inspanning. Vergelijkbare patronen werden gevonden voor spraak- en non-spraakbewegingen, hoewel de reacties sterker waren voor de knopdruktaak dan voor de syllabeproductietaak.

Figuur 4 toont de resultaten van de beamformer bronalayse. De bij benadering lokatie van de piekactivatie voor elk van de twee taken en complexiteitsniveaus is weergegeven op een generiek transparant brein. Het is duidelijk dat beide spraak- en non-spraakbewegingen resulteerden in zeer vergelijkbare gelokaliseerde activaties in de linker precentrale cortex, wat een significante overlapping suggereert tussen de neurale populaties die geactiveerd zijn in beide taken, althans wat betreft bewegingsvoorbereiding. 


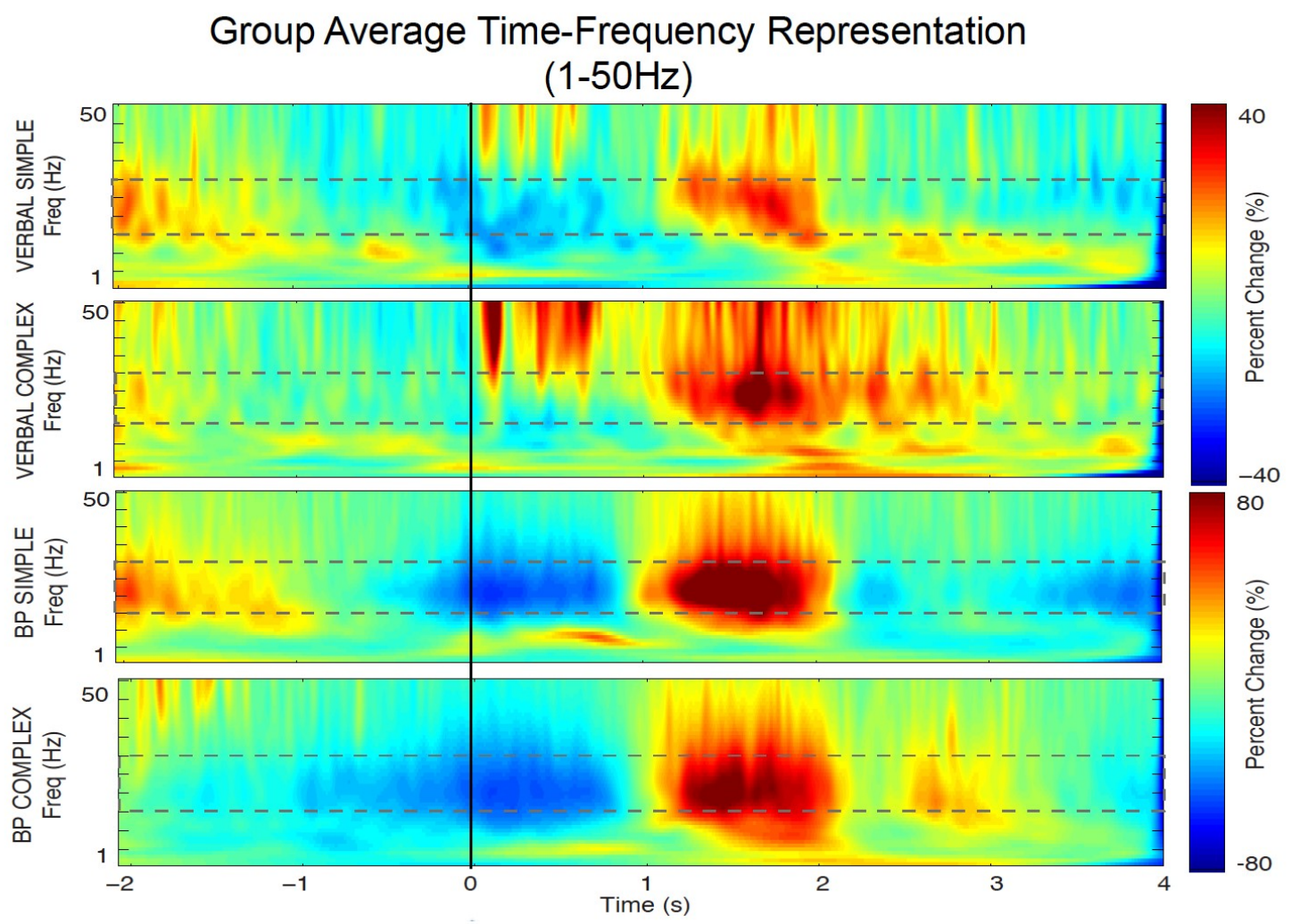

Figuur 2: Tijd-frequentiegrafieken van neurale oscillaties verbonden aan spraak- en knopdrukbewegingen in typisch vloeiende sprekers.

Hoewel de in deze studie verkregen gegevens preliminair van aard zijn, laten zij duidelijk de bruikbaarheid zien van MEG voor het bestuderen van neurale processen gedurende zowel spraak- als non-spraakplanning. Met name laten ze zien hoe MEG kan gebruikt worden om het tijdsverloop van dergelijke activaties van stimuluspresentatie tot bewegingsvoltooiing te onderzoeken. Dit voordeel van MEG wordt nader toegelicht in de tweede studie die we navolgend presenteren.

\section{Studie 2: het karakteriseren van neurale oscillaties in het spraak- motornetwerk van volwassenen die stotteren gedurende spraak- voorbereiding}

Het doel van deze studie was gedeeltelijk om MEG te gebruiken voor het karakteriseren van neurale oscillaties in het spraak-motornetwerk van volwassenen die stotteren gedurende de voorbereiding op en uitvoering van overte spraakproductie. We rekruteerden twaalf vol- 


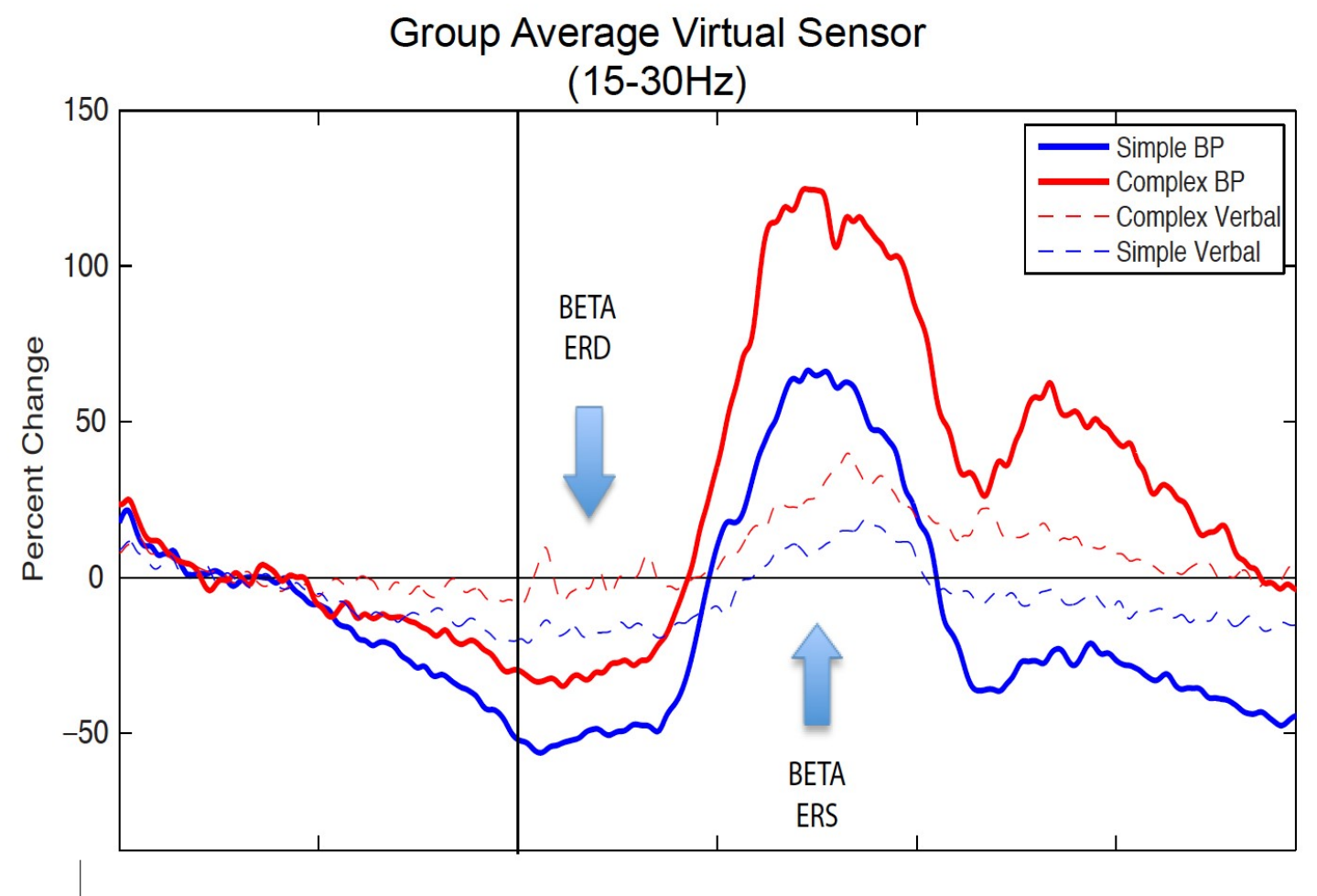

Figuur 3: Grafiek van tijdsprocentuele veranderingen van bèta-synchronisatie en desynchronisatie gedurende spraak- en knopdruktaken in typisch vloeiende sprekers.

wassenen die stotteren met een score van ten minste 'mild' op de Stuttering Severity Index (SSI-IV) (Riley, 2009) en zelf-gerapporteerd stotteren vanaf de vroege kindertijd. Ter vergelijking werden ook twaalf gematchte typisch vloeiende sprekers gerekruteerd. Als onderdeel van het experiment werd aan deelnemers 220 woorden gepresenteerd, individueel geselecteerd voor elke stotterende deelnemer gebaseerd op een beoordeling van stotteranticipatie. Deelnemers in de controlegroep werd hetzelfde woord gepresenteerd als hun gematchte stotterende deelnemer. Deelnemers werd gevraagd het stimuluswoord uit te spreken ingebed in een draagzin. We analyseerden alfa $(8-13 \mathrm{~Hz})$ en bèta $(15-25 \mathrm{~Hz})$ neurale oscillerende activiteit voorafgaand aan en na spraakproductie.

Onze data lieten zien dat visuele woordpresentatie bilaterale alfa-onderdrukking induceerde in de auditieve cortex, bèta-onderdrukking in de mond-motorcortex, en zowel alfaals bèta-onderdrukking in de visuele cortex. Zoals zichtbaar in Figuur 5, lieten deze frequenties differentiële tijdsverlopen zien tussen de voornoemde regio's. Ten behoeve van deze preliminaire analyse hebben we de groepsgemiddele timing van de eerste onderdrukkingspiek van elk tijdsverloop gemeten, zoals aangegeven in Figuur 5. Dit illustreert de zeer nauwkeurige temporele veranderingen, in de orde van milliseconden, in de rekrutering van deze regio's. Deze mogelijkheid om temporale veranderingen met een hoge graad van nauw- 


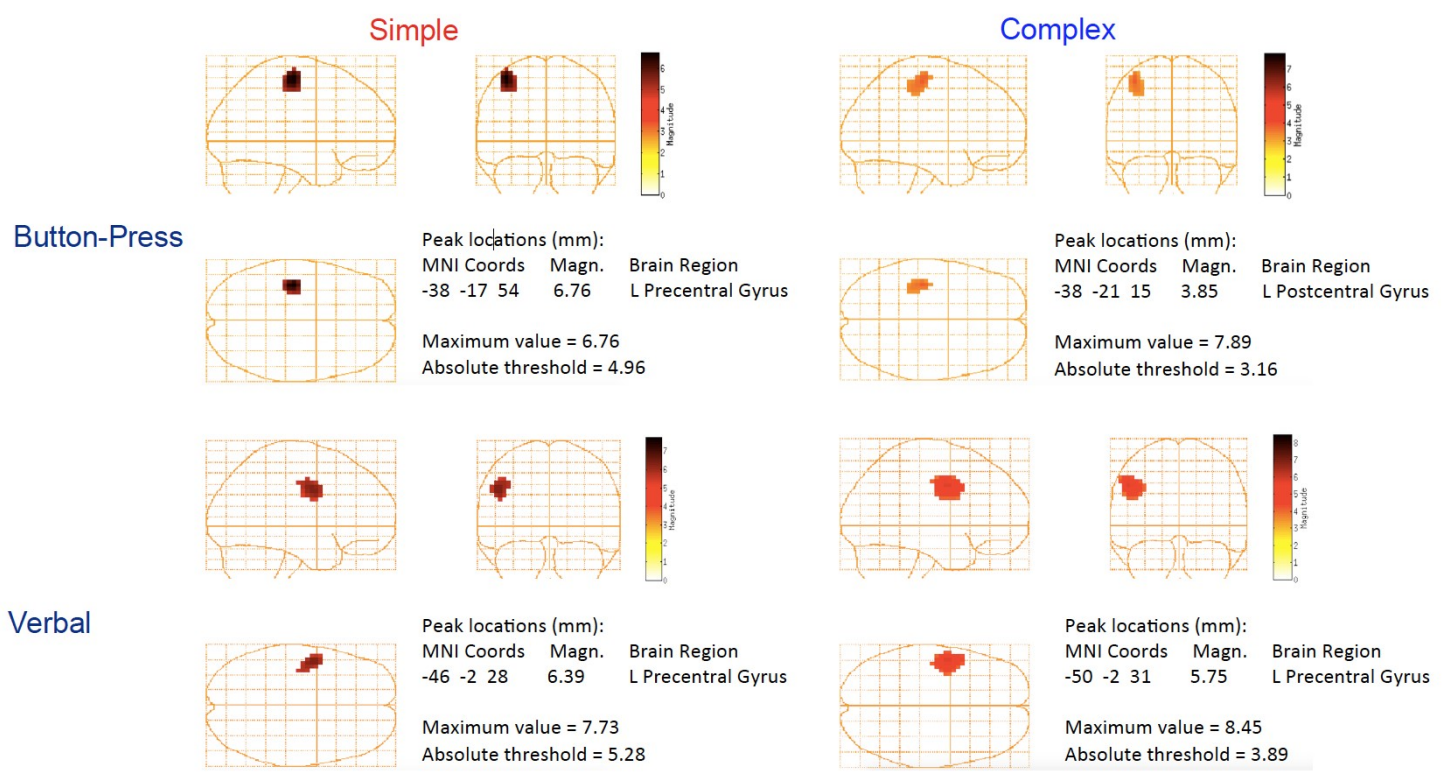

Figuur 4: Beamformer hersenbeelden tonen de lokalisatie van corticale activatie geassocieerd met neurale oscillatie tijdens eenvoudige en complexe spraak- en knopdruktaken in typisch vloeiende sprekers.

keurigheid te analyseren is een van de grote voordelen van MEG. Analyse laat zien dat onmiddelijk na stimuluspresentatie (bij de 0 seconde markering), de bèta-onderdrukking eerst werd waargenomen in de visuele cortex, gevolgd door bèta-onderdrukking in de mondregio van de motorcortex, en tenslotte alfa-onderdrukking in de auditieve cortex. Opmerkelijk genoeg beginnen deze neurale piek-oscillaties significant eerder dan de daadwerkelijke spraakproductie, die niet initieert voor meer dan 1 seconde na stimuluspresentatie. Op dit moment zijn er geen groepsverschillen tussen stotterende en niet-stotterende volwassenen waargenomen, maar we zijn momenteel bezig met het fijnkorrelige vergelijken van de auditieve en motorische betrokkenheid tussen deze groepen. Bijvoorbeeld, verder onderzoek van de gegevens lijkt te suggereren dat het tijdsverloop van de rechter motorcortex (solide zwarte lijn) in de typisch vloeiende sprekers aanzienlijk verminderd is en vlakker lijkt (minder onderdrukking, Figuur 5 rechtsboven), terwijl voor de stotterende deelnemers een grotere bèta-onderdrukking is waargenomen in dezelfde regio (Figuur 5 rechtsonder). Dit zou betekenen dat in stotterende sprekers de rechter motorcortex meer betrokken is voorafgaand aan spraak, wat congruent zou zijn met eerdere waarnemingen in vroegere fMRI studies (Belyk, Kraft \& Brown, 2015). Indien bevestigd, zou onze MEG-analyse ons in staat stellen te laten zien dat deze verschillen in betrokkenheid van de motorcortex kunnen worden getimed om samen te vallen met pre-spraakbewegingsplanning. 


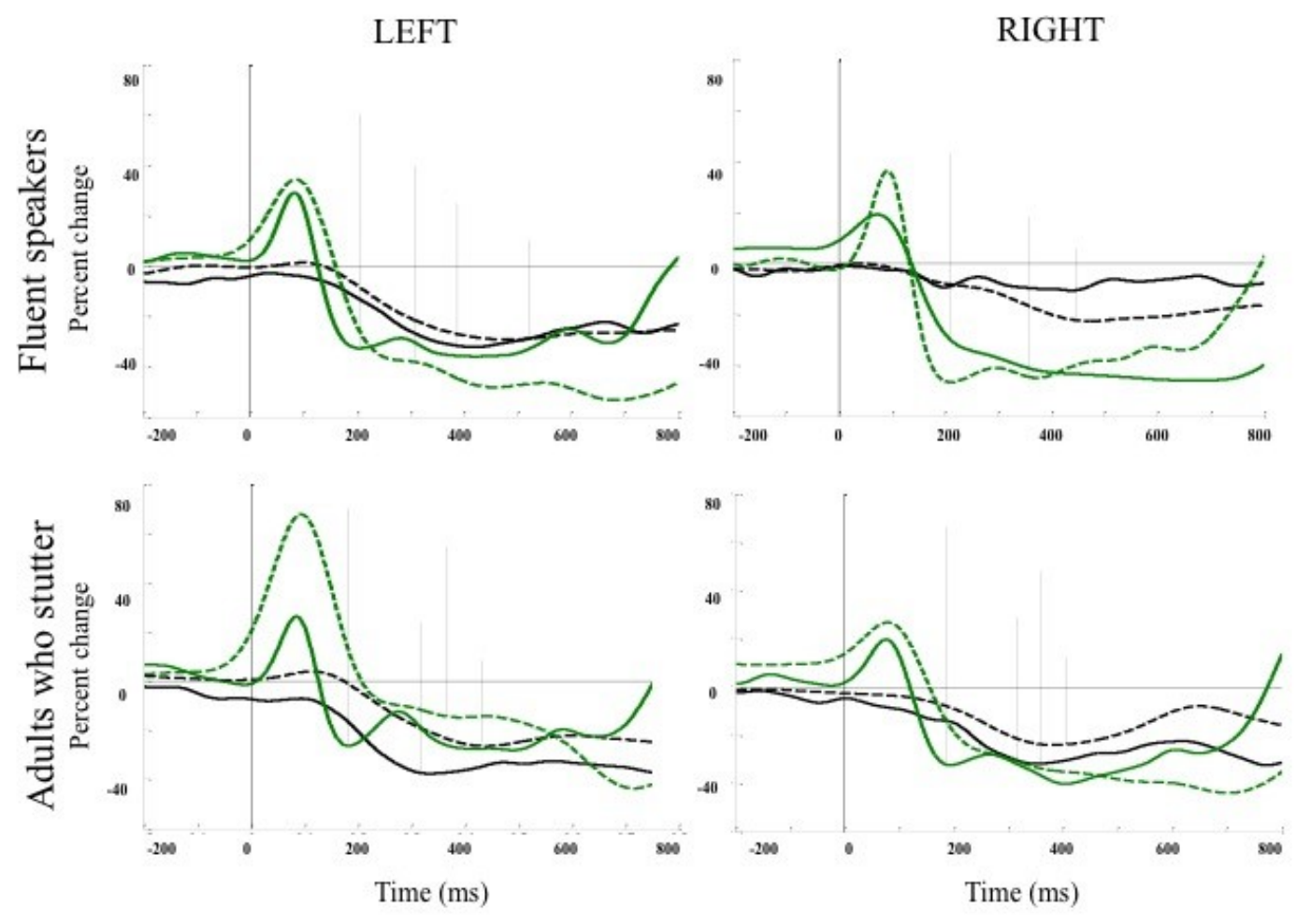

Figuur 5: Tijdsverloop van alfa (stippellijn) en bèta (vaste lijn) onderdrukking in de occipitale cortex (groen, cuneus - BA17), auditieve cortex (gestippeld zwart, BA41), en de mond-motorcortex (solide zwart, BA6), in de linker en rechter hersenhelft van stotterende en typisch vloeiende sprekers. De stimuluspresentatie vond plaats op $0 \mathrm{~ms}$ (solide verticale lijn).

\section{Conclusies}

We hebben de basisprincipes van magnetoencefalografie beschreven, en de bruikbaarheid van deze techniek laten zien voor de studie van spraak in typisch vloeiende sprekers en personen die stotteren, zowel volwassenen als kinderen. De mogelijkheid om hersenactiviteit met een zeer fijne temporele resolutie waar te nemen biedt grote voordelen om het tijdsverloop van neurale activiteit voorafgaand, gedurende, en volgend op spraak te bestuderen. Ondanks het feit dat deze beeldvormingstechniek grotendeels beperkt is tot het waarnemen van activatie op het corticale niveau, zal het belangrijke nieuwe inzichten opleveren, vooral wanneer gecombineerd met andere hersenbeeldvormingstechnieken zoals fMRI.

Het verkrijgen van een beter begrip van de neurale processen verbonden aan spraakproductie, en vooral hoe deze processen temporeel worden aangepast en onder verschillende 
omstandigheden, houdt een grote belofte in voor toepassingen in klinische interventie. Toekomstige MEG studies zullen in staat zijn te onderzoeken hoe corticale activatie in personen die stotteren verandert door behandeling en zullen ons toestaan de effecten van verschillende soorten behandeling te vergelijken. We zullen ook gaan inzien of veranderingen in corticale activiteit in de tijd verbonden is met herstel van stotteren, mogelijk leidend to beter voorspelbare variabelen voor stotterchroniciteit bij jonge kinderen. Het zal nodig zijn voor onderzoeksteams om zowel fundamentele als klinische wetenschappers relevante klinische onderzoeksvragen te laten formuleren, en de studies te ontwerpen op een manier die zowel de huidige klinische praktijk als strikt wetenschappelijke methoden reflecteren. Dit is een uitdagende doelstelling, maar een die steeds meer binnen bereik is omdat de techniek en inzicht in de etiologie van het stotteren meer en meer verfijnd worden.

\section{Dankwoord}

Het onderzoek gerapporteerd in dit artikel werd ondersteund door subsidies aan de eerste auteur afkomstig van het Canadian Institutes of Health Research en de Natural Sciences and Engineering Research Council. De auteurs danken mevrouw Cecilia Jobst en mevrouw Soonji Kwon voor hun hulp tijdens het verzamelen en analyseren van gegevens.

\section{Referenties}

Alho, J., Lin, F. H., Sato, M., Tiitinen, H., Sams, M., \& Jääskeläinen, I. P. (2014). Enhanced neural synchrony between left auditory and premotor cortex is associated with successful phonetic categorization. Frontiers in Psychology, 5, 394. http://doi.org/10.3389/fpsyg.2014.00394

Alm, P.A. (2004). Stuttering and the basal ganglia circuits: A critical review of possible relations. Journal of Communication Disorders, 37(4), 325-369.

Ambrose, N. G., Cox, N. J., \& Yairi, E. (1997). The genetic basis of persistence and recovery in stuttering. Journal of Speech Language and Hearing Research, 40(3), 567-580.

Beal, D.S., Quraan, M.A., Cheyne, D.O., Taylor, M.J., Gracco, V.L., \& De Nil, L.F. (2015) Speechinduced suppression of evoked auditory fields in children who stutter. NeuroImage, 54 (4), pp. 2994-3003.

Belyk, M., Kraft, S. J., \& Brown, S. (2015). Stuttering as a trait or state - an ALE metaanalysis of neuroimaging studies. The European Journal of Neuroscience, 41(2), 275-84. http://doi.org/10.1111/ejn.12765

Bloodstein, O., \& Bernstein-Ratner, N. (2008). A handbook on stuttering (6th ed.). Clifton Park, NY: Delmar.

Bowers, A., Saltuklaroglu, T., Harkrider, A., \& Cuellar, M. (2013). Suppression of the $\mu$ rhythm during speech and non-speech discrimination revealed by independent component analysis: Implications for sensorimotor integration in speech processing. PloS One, 8(8), e72024. http://doi.org/10.1371/journal.pone.0072024 
Cassim, F., Monaca, C., Szurhaj, W., Bourriez, J., Defebvre, L., Derambure, P., \& Guieu, J. (2001). Does post-movement beta synchronization reflect an idling motor cortex? Neuroreport, 12(17), 3859-3863.

Chang, S. E., Kenney, M. K. Loucks, T. M. J., \& Ludlow, C. L. (2009). Brain activation abnormalities during speech and non-speech in stuttering speakers. NeuroImage, 46(1), 201-212.

Cheyne, D. (2013). MEG studies of sensorimotor rhythms: a review. Experimental Neurology, 245, 27-39. http://doi.org/10.1016/j.expneurol.2012.08.030

Cheyne, D. O. \& Papanicolaou, A. C. (2015). Chapter II: Magnetoencephalography and magnetic source imaging. In A. C. Papanicolaou (Eds), Functional Brain Imaging in Cognitive Neurosciences and Neuropsychology. Oxford, UK, Oxford University Press.

De Nil, L. F. (1999). Stuttering: A neurophysiological perspective. In N. Bernstein Ratner \& E. C. Healey (Eds.), Stuttering research and practice: Bridging the gap (pp. 85-102). Mahwah, NJ: Erlbaum.

De Nil, L. F. (2004). Recent developments in brain imaging research in stuttering. In B. Maassen, H. F. M. Peters \& R. Kent (Eds.), Speech motor control in normal and disordered speech. Proceedings of the fourth international speech motor conference (pp. 150-155). Oxford: Oxford.

De Nil, L.F. \& Beal, D. (2015). Brain Imaging Studies of Developmental Stuttering: A Review (pp. 46-55). In Huntley Bahr R. \& Silliman, E.F. (Eds), Handbook of Communication Disorders. Routledge: New York

De Nil, L. F., Jokel, R. \& Rochon, E. (2007). Etiology, symptomatology, and treatment of neurogenic stuttering. In: Edward G. Conture and Richard F. Curlee (Eds.). Stuttering and related disorders of fluency (3rd ed., pp. 326-343). New York, Thieme.

De Nil, L. F., Kroll, R. M. \& Houle, S. (2001). Functional neuroimaging of cerebellar activation during single word reading and verb generation in stuttering and nonstuttering adults. Neuroscience Letters, 302(2-3), 77-80.

Drayna, D., Kilshaw, J. \& Kelly, J. (1999). The sex ratio in familial persistent stuttering. American Journal of Human Genetics, 65 (5), 1473-1475.

Dziewas, R., SJörJös, P., Ishii, R., Chau, W., Henningsen, H., Ringelstein, E., ... \& Pantev, C. (2003). Neuroimaging evidence for cortical involvement in the preparation and in the act of swallowing. NeuroImage, 20(1), 135-144.

Engel, A. K., \& Fries, P. (2010). beta-band oscillations - signalling the status quo? Current Opinion in Neurobiology, 20(2), 156-65. http://doi.org/10.1016/j.conb.2010.02.015

Etchell, A. C., Johnson, B. W., \& Sowman, P. F. (2014). Behavioral and multimodal neuroimaging evidence for a deficit in brain timing networks in stuttering: A hypothesis and theory. Frontiers in Human Neuroscience, 8, 467.

http://doi:10.3389/fnhum.2014.00467

Furlong, P. L., Hobson, A. R., Aziz, Q., Barnes, G., Singh, A., Hillebrand, A., ...\& Hamdy, S. (2004). Dissociating the spatio-temporal characteristics of cortical neuronal activity associated with human volitional swallowing in the healthy adult brain. NeuroImage, 22(4), 1447-1455.

Gehrig, J., Wibral, M., Arnold, C., \& Kell, C. A. (2012). Setting up the speech production 
network: How oscillations contribute to lateralized information routing. Frontiers in Psychology, 3, 169. http://doi.org/10.3389/fpsyg.2012.00169

Gilbertson, T., Lalo, E., Doyle, L., Di Lazzaro, V., Cioni, B., \& Brown, P. (2005). Existing motor state is favored at the expense of new movement during 13-35 hz oscillatory synchrony in the human corticospinal system. Journal of Neuroscience, 25(34), 7771-7779. http://doi:10.1523/JNEUROSCI.1762-05.2005

Hari, R., Salmelin, R., Mäkelä, J. P., Salenius, S., \& Helle, M. (1997). Magnetoencephalographic cortical rhythms. International Journal of Psychophysiology, 26(1-3), 51-62. http://doi:10.1016/S0167-8760(97)00755-1

Hämäläinen, M., Hari, R., Ilmoniemi, R. J., Knuutila, J., \& Lounasmaa, O. V. (1993). Magnetoencephalography-theory, instrumentation, and applications to noninvasive studies of the working human brain. Reviews of Modern Physics, 65(2), 413-497.

Jenkinson, N., \& Brown, P. (2011). New insights into the relationship between dopamine, beta oscillations and motor function. Trends in Neurosciences, 34(12), 611-8. http://doi.org/10.1016/j.tins.2011.09.003

Jenson, D., Thornton, D., Saltuklaroglu, T., \& Harkrider, A. (2014). Speech perception, production, and the sensorimotor mu rhythm. Proceedings of the 2014 Biomedical Sciences and Engineering Conference, 1-4. http://doi.org/10.1109/BSEC.2014.6867736

Johnson, W. (1959). Stuttering in children and adults: Thirty years of research at the University of Iowa. Minnesota: University of Minnesota Press.

Jurkiewicz, M. T., Gaetz, W. C., Bostan, A. C., \& Cheyne, D. (2006). Post-movement beta rebound is generated in motor cortex: Evidence from neuromagnetic recordings. $\mathrm{Neu}$ roImage, 32(3), 1281-9. http://doi.org/10.1016/j.neuroimage.2006.06.005

Kilavik, B. E., Confais, J., Ponce-Alvarez, A., Diesmann, M., \& Riehle, A. (2011). Evoked potentials in motor cortical local field potentials reflect task timing and behavioral performance. Journal of Neurophysiology, 105(1), 501.

http://doi:10.1152/jn-z9k-0551-corr.2011

Liljeström, M., Jan, K., Stevenson, C., \& Salmelin, R. (2014). Dynamic reconfiguration of the language network preceding onset of speech in picture naming. Human Brain Mapping, 36(3), 1202 - 1216. http://doi.org/10.1002/hbm.22697

Loose, R., \& Probst, T. (2001). Velocity not acceleration of self-motion mediates vestibular - visual interaction. Perception, 30(4), 511-518.

Mersov, A.M., Jobst, C., Cheyne, D.O., De Nil, L. (2016). Sensorimotor oscillations prior to speech onset reflect altered motor networks in adults who stutter. Frontiers in Human Neuroscience, 10 (SEP2016), art. no. 443.

Mersov, A.M., Cheyne, D.O., Jobst, C. \& De Nil, L. Neural oscillatory characteristics of motor preparation prior to dysfluent and fluent utterances in adults who stutter. Journal of Fluency Disorders. (ingediend).

Murthy, V. N., \& Fetz, E. E. (1992). Coherent 25- to 35-hz oscillations in the sensorimotor cortex of awake behaving monkeys. Proceedings of the National Academy of Sciences of the United States of America, 89(12), 5670-5674.

Murthy, V. N., \& Fetz, E. E. (1996). Oscillatory activity in sensorimotor cortex of awake monkeys: Synchronization of local field potentials and relation to behavior. Journal of Neu- 
rophysiology, 76(6), 3949-3967.

Murthy, V. N., \& Fetz, E. E. (1996). Synchronization of neurons during local field potential oscillations in sensorimotor cortex of awake monkeys. Journal of Neurophysiology, 76(6), 3968-3982.

Orton, S.T. (1928). A physiological theory of reading disability and stuttering in children. New England Journal of Medicine, 199, 1046-1052.

Ozge, A., Toros, F., \& Comelekoglu, U. (2004). The role of hemispheral asymmetry and regional activity of quantitative EEG in children with stuttering. Child Psychiatry \& Human Development, 34(4), 269-280.

Pfurtscheller, G., \& da Silva, F. H. (1999). Event-related EEG/MEG synchronization and desynchronization: Basic principles. Clinical Neurophysiology, 110(11), 1842-1857. http://doi.org/10.1016/S1388-2457(99)00141-8

Riley, G., \& Bakker, K. (2009). Stuttering Severity Instrument: SSI-4 (4th ed.). Austin: Pro-Ed.

Salmelin, R., Hari, R., Lounasmaa, O. V., \& Sams, M. (1994). Dynamics of brain activation during picture naming. Nature, 368, 463-465.

Salmelin, R., Schnitzler, A., Schmitz, F, \& Freund, H. (2000). Single word reading in developmental stutterers and fluent speakers. Brain, 123, 1184-202.

Sanes, J. N., \& Donoghue, J. P. (1993). Oscillations in local field potentials of the primate motor cortex during voluntary movement. Proceedings of the National Academy of Science of the United States of America, 90(10), 4470-4474.

Schnitzler, A., Timmermann, L., \& Gross, J. (2006). Physiological and pathological oscillatory networks in the human motor system. Journal of Physiology Paris, 99(1), 3-7. http://doi:10.1016/j.jphysparis.2005.06.010

Sheehan, J. G. (1953). Theory and treatment of stuttering as an approach-avoidance conflict. The Journal of Psychology Interdisciplinary and Applied, 36(1), 27-49.

Shibukawa, Y., Shintani, M., Kumai, T., Suzuki, T. \& Nakamura, Y. (2004). Cortical neuromagnetic fields preceding voluntary jaw movements. Journal of Dental Research, 83(7), 57

Sowman, P. F., Crain, S., Harrison, E., \& Johnson, B. W. (2012). Reduced activation of left orbitofrontal cortex precedes blocked vocalization: A magnetoencephalographic study. Journal of Fluency Disorders, 37(4), 359-65. http://doi.org/10.1016/j.jfludis.2012.05.001

Tzagarakis, C., Ince, N. F., Leuthold, A. C., \& Pellizzer, G. (2010). beta-band activity during motor planning reflects response uncertainty. The Journal of Neuroscience: The Official Journal of the Society for Neuroscience, 30(34), 11270-7. http://doi.org/10.1523/JNEUROSCI.6026-09.2010

Vanhoutte, S., Cosyns, M., Van Mierlo, P., Batens, K., Corthals, P., De Letter, M., ... Santens, P. (2016). When will a stuttering moment occur? The determining role of speech motor preparation. Neuropsychologia, 86, 93-102. http://doi:10.1016/j.neuropsychologia.2016.04.018

Yairi, E., \& Ambrose, N. G. (1999). Early childhood stuttering I: Persistency and recovery rates. Journal of Speech, Language, \& Hearing Research, 42(5), 1097-1112.

Yairi, E., \& Ambrose, N. (2013). Epidemiology of stuttering: 21st century advances. Journal of Fluency Disorders, 38 (2), 66-87. 